\title{
Diabetes and Risk of Community-Acquired Respiratory Tract Infections, Urinary Tract Infections, and Bacteremia
}

\author{
Reimar W. Thomsen ${ }^{*}$ and Anil Mor
}

Department of Clinical Epidemiology, Institute of Clinical Medicine, Aarhus University Hospital, Aarhus, Denmark

\begin{abstract}
This review provides an update on the risk of several important community-acquired infections seen in patients with diabetes: respiratory tract infections, urinary tract infections, and bacteremia. Respiratory tract infections: Recent epidemiological evidence shows a modest (1.25 to 1.75-fold) risk increase for hospitalization with pneumonia associated with diabetes. The increase of risk for tuberculosis is of similar magnitude in highly developed countries, and possibly higher in low-income countries. Poor glycemic control and long diabetes duration predict higher risk for both pneumonia and tuberculosis. Limited data is available for diabetes and influenza, yet both influenza and pneumococcal vaccination is recommended in patients with diabetes.
\end{abstract}

Urinary tract infections: The risk of asymptomatic bacteriuria and cystitis is 1.5 to 2 times increased in diabetes patients, while their risk of pyelonephritis may be 2 to 4 times increased. Treatment of asymptomatic bacteriuria in diabetes is generally not recommended. Diabetes duration and chronic complications including cystopathy appear to be more important risk factors than current glycemic control, but further evidence is needed. Modifiable risk factors for urinary tract infection are the same as in persons without diabetes.

Bacteremia: The risk of bacteremia due to pneumococci is approximately 1.5 times increased in diabetes, similar to the increased risk for pneumonia. In comparison, diabetes is associated with 2.5 to 3 times increased risk for bacteremia due to E. coli and other enterobacteria, often due to a urinary tract focus. Diabetes is also associated with a 2 times increased risk for hemolytic streptococcal bacteremia, and 3 times increased risk for invasive group B streptococcal infection. Limited data is available for staphylococcal bacteremia.

Conclusions: Increased infection surveillance and unmeasured confounding factors among diabetic patients may contribute to the observed increased infection risk, yet outcomes following infection are similar or worse in diabetes patients. In conclusion, there is epidemiological evidence that individuals with diabetes have a substantially increased risk of a number of important infections. Clinicians should remain vigilant for infections in this increasing group of patients.

Keywords: Diabetes, hyperglycemia, infection, risk, epidemiology, bacteremia, sepsis, urinary tract infection, pneumonia, risk.

\section{INTRODUCTION}

"After a careful history had been taken, the patient was given a complete physical examination. Special attention was directed to the finding of foci of possible infection. The teeth, accessory sinuses, chest and digestive system were examined clinically, as well as by $x$-ray. Special consideration was given to a biliary tract infection, constipation and chronic appendicitis. If any source of septic absorption was located, it was appropriately treated, since such conditions may lower carbohydrate tolerance."

Frederick G. Banting. Nobel Lecture delivered in Stockholm on September $15^{\text {th }}, 1925$. About clinical routine examinations at the first three diabetes clinics in Toronto.

*Address correspondence to this author at the Department of Clinical Epidemiology, Institute of Clinical Medicine, Aarhus University Hospital, Olof Palmes Alle 43-45, DK-8200 Aarhus, Denmark; Tel: +45 8716 8204; Fax: +45 8716 7215; E-mail: rwt@dce.au.dk
Diabetes mellitus is a major and increasing public health and clinical problem [1-3]. Prevalence of diabetes has tripled in the last 3 decades, and according to the World Health Organization approximately 346 million people are now living with diabetes worldwide. According to an estimate the world prevalence of diabetes among adults will increase to $7.7 \%$ or 439 million adults by 2030 , with a $69 \%$ increase in numbers of adults with diabetes in developing countries and a $20 \%$ increase in developed countries [4]. Diabetes affects the function of multiple organ systems and thus imposes a tremendous burden on the individual with diabetes and on health care systems. Individuals with diabetes have a two- to fourfold increased risk of cardiovascular and cerebrovascular disease [5], and diabetes is the leading cause of end-stage renal disease, nontraumatic lower extremity amputations, and adult blindness in large parts of the Western world [6]. Diabetes was responsible for $6.8 \%$ of total global deaths in all age groups in 2010 [7]. A multi-center observational study showed that only $13 \%$ of diabetic patients died solely due to diabetes whereas $87 \%$ died of diabetes complications, including infections [8].

It has long been a common clinical belief that diabetes increases the risk of infections [9-11]. Until the 2000s, this 
belief was not supported by much epidemiological evidence, as stated in a review of the issue in the New England Jounal of Medicine in 1999 [12]. During the last decade however, there has been an increasing amount of new evidence and research interest in important infections amongst those with diabetes $[13,14]$, although in some areas the evidence is still scant and of poor quality. There is also new evidence that hyperglycemia is associated with inflammation, altered immune function, and increased severity of infection [15, 16]. Rare infections that occur almost exclusively in diabetic patients, such as malignant otitis externa due to $P$. aeruginosa, rhinocerebral mucormycosis, the fungal infection zygomycosis, certain infections with gas-forming microorganisms e.g. emphysematous pyelonephritis and cholecystitis [17], and the tropical diabetic hand syndrome [18] are covered in more detail elsewhere $[12,19]$.

\section{DIABETES AND THE RISK OF COMMUNITY- ACQUIRED RESPIRATORY TRACT INFECTIONS}

Respiratory Tract Infection (RTI) is a leading cause of morbidity, mortality, and cost of care worldwide. Combined with influenza, pneumonia is the eighth leading cause of death in United States and the most frequent cause of death due to infectious disease [20]. During the past decade, hospitalizations with pneumonia have increased by $20-50 \%$ in Western populations [21-24], possibly related to an increasing population prevalence of comorbidities such as cancer, heart failure, chronic obstructive pulmonary disease (COPD), and diabetes. On the population level, patients with diabetes may be more susceptible to RTIs due to a number of mechanisms. These include higher age, unhealthy lifestyle such as smoking and alcohol overuse, a generally decreased immune function, increased risk of aspiration due to diabetic gastroparesis, possibly impaired lung function and pulmonary microangiopathy, and frequent comorbidity like renal failure, stroke sequelae, and chronic heart failure [25, 26]. In their 2011 Standards of Medical Care in Diabetes [27], the American Diabetes Association states that there are limited studies reporting the morbidity and mortality of influenza and pneumococcal pneumonia specifically in people with diabetes, citing an 11 year old review of this topic [28]. However, new evidence has accumulated during the last decade.

\section{Diabetes and Pneumonia}

Five cohort studies since 2003 found that diabetes is a risk factor for pneumonia, with relative risks (RRs) ranging from 1.26 to 1.75 [26, 29-33], while three older studies had failed to find an association [34-36]. A Dutch cohort study compared diabetic patients with an age-matched control group of hypertensive patients in 195 general practices. The authors found that diabetic patients had a greater risk of lower respiratory tract infections diagnosed in primary care, including pneumonia, acute bronchitis, influenza, pleuritis, and exacerbations of chronic lung disease (adjusted odds ratio $(\mathrm{OR})$ for patients with type 1 diabetes $=1.42(95 \% \mathrm{CI}$ $0.96-2.08)$ and for patients with type 2 diabetes $=1.32(95 \%$ CI, 1.13-1.53)) [32]. In a large Canadian cohort study, Shah et al. compared all persons with diabetes in Ontario to matched nondiabetic persons $(n=513,749$ in each group) [29]. Persons with diabetes had an increased risk of pneumonia-related hospitalization or physician claims for pneumonia treatment $(\mathrm{RR}=1.46 ; 99 \%$ CI 1.42-1.49), yet comorbidity adjustment was not possible in that study. Jackson et al. reported that the adjusted RR for hospitalizations for community-acquired pneumonia was 1.52 (95\% CI 1.29-1.78) among persons with diabetes compared to persons without diabetes, based on 46,237 persons aged $\geq 65$ years enrolled in a single health maintenance organization in Washington State [30]. Kornum et al. did a case-control study of 34,239 patients with a pneumonia-related hospitalization and 342,390 population controls in Denmark [26]. The adjusted RR for pneumoniarelated hospitalization among persons with diabetes was 1.26 (95\% confidence interval (CI) 1.21-1.31). The adjusted RR was larger for type 1 diabetes: 4.43 (95\% CI 3.40-5.77), vs 1.23 (95\% CI $1.19-1.28)$ for persons with type 2 diabetes. In a recent large analysis of individual-participant data from 97 prospective studies that had information about diabetes or fasting blood-glucose level at baseline, the age-, smoking-, and BMI-adjusted hazard ratio for death from pneumonia associated with presence of diabetes was 1.67 (95\% CI 1.451.92) (compared with hazard ratio for infections other than pneumonia: 2.39 (95\% CI 1.95-2.93)) [37]. In conclusion, there is evidence that diabetes is associated with a moderately $(25 \%-75 \%)$ increase in the relative risk of pneumonia-related hospitalization. Several studies show that longer duration of diabetes and poor glycemic control increase the risk of pneumonia-related hospitalization [26, 33]. Moreover, several studies report an increased risk of death associated with pneumonia hospitalization in patients with diabetes or hyperglycemia [38-41]. Yende et al. analysed two different cohorts and found that diabetes was associated with a 1.3 to 1.9 times higher risk of death within the first year following CAP [39]. One of their cohort analyses suggested that increased mortality from diabetes was not due to an altered immune response, but rather to worsening of pre-existing cardiovascular and kidney disease. In a Danish population-based study, mortality among type 2 diabetic $v s$ other patients was $19.9 \%$ vs $15.1 \%$ in other patients 30 days after pneumonia admission and $27.0 \% \mathrm{vs}$ $21.6 \%$ after 90 days, corresponding to adjusted 30- and 90day mortality rate ratios (MRRs) of 1.16 (95\% CI 1.07-1.27) and 1.10 (95\% CI 1.02-1.18). In contrast, presence of type 2 diabetes did not predict pulmonary complications or bacteremia [40].

\section{Diabetes and Influenza}

Few epidemiologic studies provide data specifically on influenza risk in diabetes. As mentioned above, a Dutch cohort study found that diabetic patients in general practice had a 1.3 to 1.4 higher risk of lower respiratory tract infection including influenza [32]. Obesity and type 2 diabetes are closely associated [1], and in the recent influenza A (H1N1) pandemic, both diabetes and obesity have been highly prevalent among patients with very severe episodes of influenza A (H1N1) [42] and among those with bacterial pneumonia in fatal influenza A (H1N1) cases [43]. Obese individuals may have increased susceptibility to lower respiratory tract infection due to impaired $\mathrm{T}$ and $\mathrm{B}$ cellmediated immune responses, a higher risk of aspiration, reduced lung volume, and an altered ventilation pattern [4446]. Notwithstanding, a recent large cohort study using the UK General Practice Research Database found 
approximately $20 \%$ decreased rates of any influenzaassociated pneumonia diagnosis among overweight and obese individuals, whereas women with type 2 diabetes in contrast had 1.37 times (95\% CI 1.08-1.72) increased rates, and even more (1.47 times) if they were also obese [47]. A recent Danish cohort study found that moderate obesity (body mass index (BMI) 30.0-34.9) was associated with a 1.4-fold (95\% CI 1.2-1.7) higher risk of a pneumonia-related hospitalization among men, while severe obesity (BMI $\geq$ 35.0) was associated with a 2.0-fold (1.4-2.8) higher risk; only weak associations were observed among women [48]. Importantly, adjustment for chronic diseases including diabetes diagnosed during follow-up eliminated the associations between obesity and pneumonia risk [48]. These UK and Danish results suggest that the apparently increased influenza and pneumonia risk associated with obesity may be explained by the occurrence of diabetes and other comorbidity. On the other hand, it remains uncertain to which degree severe obesity may explain any apparent association between diabetes and severe influenza or pneumonia, since confounder or mediator data on anthropometric measures are often not available in large diabetes database studies.

\section{Influenza and Pneumococcal Vaccination in Diabetes - Recommendations and Effectiveness}

The above data may emphasize the value of influenza and pneumococcal immunization in diabetic patients, particularly for those with long diabetes duration and associated obesity, and the importance of good glycemic control. The Centers for Disease Control and Prevention (CDC) Advisory Committee on Immunization Practices recommends influenza vaccination for all children and adults with diabetes (http://www.cdc.gov/vaccines/recs/) [49]. In their 2011 Standards of Medical Care in Diabetes [27], the American Diabetes Association (ADA) recommends annually influenza vaccine to all diabetic patients at least 6 months of age, and pneumococcal polysaccharide vaccine to all diabetic patients $>=2$ years of age. A one-time revaccination is recommended for individuals $>64$ years of age previously immunized when they were $<65$ years of age if the vaccine was administered $>5$ years ago. It is generally believed that people with diabetes have appropriate serologic responses to these vaccinations [27]. However, Nam and colleagues recently studied the humoral immune response to the inactivated influenza A (H1N1) 2009 monovalent vaccine in patients with Type 2 diabetes mellitus in Korea, and suggested to consider a two-dose vaccination for older patients and those with long duration of diabetes as they appeared to have low seroconversion rates [50].

A Dutch nested case-control study found that influenza vaccination was associated with a 54-58\% risk reduction of any acute cardiopulmonary hospitalization or death among adults with diabetes [51]. However, there is a high risk of uncontrolled healthy vaccine user bias in observational studies [52]. As noted in two recent Cochrane reviews from 2010, influenza vaccines have a modest effect in reducing influenza symptoms and working days lost in healthy adults [53], whereas there are no adequately powered randomized controlled trials to assess the effectiveness of influenza vaccines in preventing influenza-related hospital admissions, complications and mortality in individuals aged 65 years or older [54]. Polysaccharide pneumococcal vaccines appear effective in preventing invasive pneumococcal disease, although the efficacy may be poorer in adults with comorbidity. The efficacy of pneumococcal vaccines against pneumonia or death in adults with or without chronic illness including the elderly is inconclusive [55].

\section{Diabetes and Tuberculosis}

In the pre-insulin era, tuberculosis used to be a very frequent cause of death in diabetic patients [56-58]. In 1928, Jacobsen reviewed the clinical course of the first 251 diabetic patients ever treated with insulin in Denmark [59]. Of 34 early deaths within four weeks after treatment was started, 14 diabetic patients died of infection (among these five of tuberculosis, and three of pneumonia). Early studies of the association of diabetes and tuberculosis were hampered by selection problems and lack of control groups, but more recent studies provide some evidence that an association is truly present. A systematic review from 2007 included 9 case-control and cohort studies and found that diabetes was consistently associated with an increased risk of tuberculosis, however with widely differing relative risk estimates between 1.5 and 7.8 [60]. A more recent metaanalysis from 2008 included 13 epidemiologic studies [61]. This review found that diabetes was associated with a 3.1 (2.3-4.3) times elevated risk of tuberculosis in three cohort studies, and with odds ratios between 1.16 and 7.83 in ten case-control or cross-sectional studies. Odds ratios were $1.50,1.61$, and 1.65 , respectively, in the three largest casecontrol studies, and odds ratios increased with decreasing study size, indicating some publication bias. Most of the studies did not properly adjust for confounding factors. In a case-control analysis of 5,290 hospitalized TB cases by Pablos-Mendez et al. [62] among ethnic groups in California, adjusted TB ORs from diabetes were 0.93 (0.781.09) among Blacks, 1.31 (1.19-1.45) among Whites, and 2.95 (2.61-3.33) among Hispanics, respectively. Recently, Leung et al. [63] followed a cohort of 42,116 patients aged 65 years or more in Hong Kong; diabetes was associated with adjusted TB hazard ratios of 1.77 (1.41-2.24) for any active TB and $1.89(1.48-2.42)$ for pulmonary TB. Interestingly, diabetic subjects with hemoglobin $\mathrm{A} 1 \mathrm{c}<7 \%$ at enrollment were not at increased risk. Even newer results from highly developed countries suggest that any tuberculosis risk increase from diabetes may be lower than previously thought in this setting [64]. Dobler et al. compared the incidence of active TB in Australia between 2001 and 2006 among 802,087 people with diabetes and close to 20 million people in the general population, and found an adjusted RR of TB of 1.48 (95\% CI 1.04-2.10) in those with diabetes [64]. In a Danish population-based casecontrol study including 2,950 patients with tuberculosis and 14,274 matched population controls, the adjusted OR for active TB in diabetic versus nondiabetic individuals was only $1.18 \quad(95 \%$ CI $0.96-1.45) \quad$ [65]. Unfortunately, epidemiological studies of the diabetes-tuberculosis association are sparse in Africa, where the increasing prevalence of (often poorly controlled) diabetes may fuel a surge in tuberculosis in a region which already has the highest global incidence rate of tuberculosis [66]. FaurholtJepsen et al. recently conducted a case-control study in Tanzania, and examined diabetes among 803 confirmed 
pulmonary TB patients and 350 neighborhood controls. Diabetes was associated with a TB OR of 2.2 (95\% CI 1.53.4 ), and this association was restricted to HIV uninfected individuals [67]. Goldhaber-Fiebert et al. undertook a crosssectional analysis using the World Health Survey $(\mathrm{n}=$ 124,$607 ; 46$ countries) and estimated that in lower-income countries, individuals with diabetes are 1.8 (1.4-2.4) times more likely than non-diabetic individuals to have TB [68]. It is currently not clear if diabetes makes individuals more susceptible to initial tuberculosis infection or increases the development of active tuberculosis from latent infection [66]. Diabetes may also affect the nature and severity of tuberculosis, including infectivity and responsiveness to treatment $[60,66]$. Finally, several studies have reported a highly increased risk of multi-drug resistant tuberculosis among diabetic persons [69, 70]. In conclusion, there is growing evidence that diabetes is associated with a moderately to highly (RRs between 1.5 and 3.0 in most studies) increased relative risk of tuberculosis, in particular if diabetes is poorly controlled. In particular for settings such as sub-Saharan Africa, where diabetes diagnosis, treatment and control is hampered by limited infrastructure and health care systems [71], it is feared that this association may exert a significant "double burden" of communicable and noncommunicable disease in the future [72-76].

\section{Conclusions on Diabetes and Community-Acquired Respiratory Tract Infections}

In conclusion, there is now much evidence that the risk of (in particular hospitalized) pneumonia is 1.3 to 1.5 times increased in diabetic patients, and their risk of tuberculosis may be 1.5 to 2 times or even more increased, depending on glycemic control and diabetes-associated comorbidity.

Influenza and pneumococcal vaccination is recommended in these patients. Treating physicians should be aware of the modestly increased risk of death in diabetic patients with lower respiratory tract infections. As in other patients, choice of antibiotic therapy should integrate local sensitivity patterns of the infecting organism, as well as place of acquisition and severity of disease.

\section{DIABETES AND THE RISK OF COMMUNITY- ACQUIRED URINARY TRACT INFECTIONS}

Urinary tract infections (UTIs) are among the most frequent community-acquired infections, with a self-reported yearly incidence of about $10 \%$ in adult women [77]. UTIs seem to be a common clinical problem in diabetic patients [78-80], but formal evidence for any association has been scarce until recently.

\section{Diabetes and Asymptomatic Bacteriuria}

As reviewed by Boyko and Lipsky in 1995 [10], a dozen of smaller case-control studies from outpatient clinics have reported that asymptomatic bacteriuria (ASB) is two- to four times more prevalent among women with diabetes than among non-diabetic women. More recent studies in the Netherlands (ASB 26\% in diabetic vs 6\% in non-diabetic females) and in Africa (32\% in diabetic vs $11 \%$ in nondiabetic) confirmed these findings [81,82], whereas another study from Italy found similar prevalences of ASB (18\% in both) in female type 2 diabetes outpatients when compared with female non-diabetic outpatients visiting a cardiology clinic [83]. In a prospective cohort study, Boyko et al. found a 2.3 times (95\% CI: 1.3-3.9) increased ASB risk for diabetic compared with nondiabetic women [84]. The spectrum of uropathogens and the profile of antibiotic resistance has shown to be similar in diabetic and nondiabetic patients with ASB [85]. Although ASB is a well-known predictor of symptomatic UTI, a randomized controlled trial in 2002 demonstrated that antibiotic treatment of ASB in women with diabetes does not reduce the risk of later UTI episodes [86].

\section{Diabetes and Cystitis}

For symptomatic urinary tract infections, not until recently have epidemiologic studies convincingly proven an association with diabetes [87, 88]. An American case-control study from 2002 reported that among 901 women aged 5575 years with acute symptomatic UTI and 913 controls, the adjusted OR for diabetes was 2.2 (95\% CI: 1.6-3.0) [89]. A doubled incidence rate of UTI associated with diabetes has been confirmed in different prospective cohort studies including thousands of postmenopausal women, for example by Brown et al. [90] (OR 1.8, 95\% CI 1.4-2.3) and Boyko et al. [84] $(\mathrm{RR}=1.8,95 \% \mathrm{CI}: 1.2-2.7)$ in the U.S. A large Canadian cohort study found that the RR of a hospitalization or physician claim for UTI associated with DM was 1.39 (95\% CI: 1.36-1.42) for cystitis and 1.95 (95\% CI: $1.78-$ 2.13) for pyelonephritis [29]. Muller et al. [32] in general practice in Holland found UTI ORs of 2.0 (95\% CI 1.5-2.6) for T1 diabetes and 1.2 (95\% CI 1.1-1.4) for type 2 diabetes. Others have suggested that the cystitis relative risk may be lower in $\mathrm{T} 1$ than $\mathrm{T} 2$ diabetic persons. In a recent study of 550 primarily premenopausal women with $\mathrm{T} 1$ diabetes, $15 \%$ reported at least one diagnosis of cystitis in the preceding 12 months; this prevalence was similar to that among nondiabetic women participants in the U.S. National Health and Nutrition Examination Survey III (NHANES III) [87]. Sexual activity rather than diabetes duration, glycemic control and diabetic complications appeared to be the main risk factor for UTI in this cohort.

\section{Diabetes and Pyelonephritis}

A population-based cohort study from Manitoba, Canada found a clearly increased incidence of hospitalizations with pyelonephritis among diabetic patients. Men and women aged over 65 years with diabetes were three to six times more likely than nondiabetic persons to be hospitalized with acute pyelonephritis, whereas diabetic patients under the age of 45 years had a 15-fold increased risk [91]. A populationbased case-control study from Washington corroborated a highly increased (adjusted OR 4.1, 95\% CI 1.6-10.9) risk of pyelonephritis associated with diabetes among healthy women aged 18 to 49 years [92]. Diabetes is also associated with worsened prognosis among elderly patients hospitalized with pyelonephritis [93, 94].

\section{The Role of Hyperglycemia in UTI Risk}

The biological mechanisms of increased UTI risk among diabetic patients remain uncertain but are likely to include immune mechanisms responsive to the quality of glycemic control $[14,95]$. The few clinical studies addressing the impact of baseline glycemic level on subsequent UTI risk had conflicting results [33, 84, 89, 90, 96, 97]. Two case-control 
studies did not find significantly more UTIs among diabetic patients with a baseline $\mathrm{HbAlc}$ level over or under $8.0 \%$ and $9.0 \%$, respectively $[89,96]$. Three cohort studies reported no major differences in relative risk estimates for UTI according to glycemic control [84, 90, 97]. Risk estimates were provided only in the study conducted by Boyko et al. [84] and tended to be increased with worse glycemic control; adjusted UTI hazard ratios for baseline $\mathrm{HbAlc}$ values of $\leq 7.5 \%, 7.6-8.5 \%$ and $>8.5 \%$ were 1.3 (95\% CI 0.7-2.3), 1.8 (95\% CI 0.9-3.3) and 1.9 (95\% CI 0.7-4.8), respectively. A recent cohort study by Benfield et al. found a $10 \%$ increased risk for hospitalizations with UTI diagnoses over 7 years of follow-up for each 1 $\mathrm{mmol} / \mathrm{L}$ increase in baseline plasma-glucose [33]. In contrast, Czaja et al. found that neither HbAlc nor intensive glycemic therapy during the Diabetes Control and Complications Trial was associated with cystitis risk in Type 1 diabetic women [87]. Very few studies have provided data on UTI risk associated with changing glycemic control in diabetic patients. A recent Danish prescription study determined the risk of antibiotictreated UTI episodes in a population-based cohort of 2737 Type 2 diabetic patients who switched from oral antidiabetic drug (OAD) to insulin therapy. Each patient was observed for 365 days before and after the switch-to-insulin date. The annual risk of antibiotic-treated UTI was high both on oral therapy (16.0\%) and insulin therapy $(16.3 \%)$, and no evidence was found that switch to insulin therapy with or without tightened glycemic control decreased the risk of UTI episodes [88].

The role of hyperglycemia is thus still unclear at present but does not seem as crucial as once thought. The evidence suggests that long diabetes duration and diabetic complications may be more important than current glycemic control, including diabetic cystopathia with retention of urine, incontinence, and an increased likelihood of instrumentation of the urinary tract [84, 88, 98]. Other important biological mechanisms may include a general predilection for certain microorganisms in diabetes, including Escherichia coli and Klebsiella species [84, $99,100]$. Geerlings et al. showed that virulent type 1-fimbriated E. coli adhere much more to the uroepithelial cells of diabetic women than other women [99]. The authors suggested that the increased binding to diabetic uroepithelial cells is caused by a difference between the type 1 fimbriae receptor on diabetic and nondiabetic uroepithelial cells.

\section{Conclusions on Diabetes and Community-Acquired Urinary Tract Infections}

In conclusion, there is much evidence that the risk of ASB and cystitis is 1.5 to 2 times increased in diabetic patients, and their risk of pyelonephritis may be 2 to 4 times increased. Treatment of ASB is generally not recommended. As in other individuals, history of previous UTI is a strong predictor for subsequent UTIs, and sexual activity and use of certain contraceptives are important modifiable UTI risk factors [87, 101]. Choice of antibiotic therapy should integrate local sensitivity patterns of the infecting organism, and rare complications as emphysematous cystitis and pyelonephritis should always be kept in mind [98].

\section{DIABETES AND THE RISK OF COMMUNITY- ACQUIRED BACTEREMIA AND SEVERE SEPSIS}

Bacteremia constitutes the most severe end of the spectrum of frequent community-acquired infections such as pneumonia and UTI, and the prevalence and thus disease burden of bacteremia has increased during the last decades analogous with diabetes. In 2003, Martin et al. reported that the annual prevalence of discharge diagnoses of septicemia, bacteremia or disseminated fungal infections in U.S hospitals had increased from 0.8 discharges/1,000 inhabitants in 1979 to 2.4 discharges $/ 1,000$ inhabitants in 2000 [102]. In 2006, septicemia was ranked the 10th leading cause of death in the United States, constituting the largest group of severe infections with known microbial etiology [20]. In Denmark, the incidence rate of microbiologically confirmed bacteremia has increased by $46 \%$ from 1992 through 2006 (from 114 to 166 episodes per 100,000 person-years). This bacteremia increase is not explained by changing demographics, but possibly explained by more frequent blood cultures and more prevalent comorbidity in the background population, including increasing prevalence of diabetes [103].

\section{Diabetes and Bacteremia/Sepsis Due to Various Pathogens}

In two early studies from the 1990s in North Carolina and Spain, the authors compared the prevalence of mixed bacteremia among all their hospitalized patients with and without diabetes over several years in a cross-sectional design $[104,105]$. Both studies found a twofold increased number of bacteremia episodes per 1000 hospital admissions in the diabetic group. No adjustment for differences in gender, age and coexisting diseases were made. In the large population-based Canadian cohort study of more than 500,000 diabetic persons and non-diabetic comparisons, the risk ratio for hospitalization with sepsis among diabetic patients was 2.5 (95\% CI: 2.2-2.7) [29]. A population-based cohort study from Sweden identified 144,000 diabetes patients in a hospital discharge registry and followed them for an average of 6.7 years for cause-specific deaths [106]. Standardized mortality rates for septicemia in diabetic patients compared with the general Swedish population were four times increased, with risk ratios ranging from $2.0(95 \%$ CI: $1.5-2.7)$ in elderly patients to 8.3 (95\% CI: 4.0-17.3) in diabetic patients hospitalized at age under 40 . These results mixed incidence and case fatality of septicemia in diabetes, however. Most studies in the 1980s and 1990s reported a similar in-hospital case-fatality following bacteremia in diabetic and non-diabetic patients, which was corroborated in recent cohort studies from Taiwan [107] and Switzerland [108]. These findings may be related to a larger proportion of diabetic cases having (prognostically more benign) urosepsis. It therefore becomes pertinent to examine the association between diabetes and specific important groups of community-acquired bacteremia due to pneumococci, enterobacteria, streptococci, and staphylococci.

\section{Diabetes and Pneumoccal Bacteremia}

S. pneumoniae accounts for at least $50 \%$ of microbiologically confirmed community-acquired pneumonias [109-112]. Pneumococcal bacteremia is probably a common feature of pneumococcal pneumonia, though it may be detected in less than ten percent of hospitalized cases [113-115]. Conversely, $80 \%$ of patients with pneumococcal bacteremia have a RTI focus [116, 117]. The increased risk of RTIs in persons with diabetes has been discussed above. As reviewed by Smith and Poland in 2000 [28], data about diabetes as risk factor for pneumococcal 
bacteremia at that time came primarily from case series. Diabetes prevalence in these studies varied from $1 \%$ to approximately $20 \%$, depending on the patients' age, type of hospital, study period, and country, as well as methods for ascertainment of diabetes. In the cross-sectional study of diabetes and diverse bacteremia from Spain [105], the prevalence of bacteremia with $S$. pneumoniae was two times increased, whereas the similar U.S. study found no increase for this group of bacteremia [104]. Marrie observed a three times higher diabetes prevalence $(21 \%$ vs $7 \%)$ in 47 bacteremic compared with 1,071 non-bacteremic cases of pneumococcal pneumonia in a Canadian university hospital [114], suggesting that diabetes is a risk factor for bacteremic pneumococcal pneumonia. In a much-cited North American case-control study of 228 immunocompetent, 18- to 64-yearold adults with invasive pneumococcal infection and 301 age-matched control subjects, Nuorti et al. [118] collected exposure data including diabetes by interview. The selfreported occurrence of diabetes was $10 \%$ in cases and $4 \%$ in controls $(\mathrm{OR}=2.5,95 \% \mathrm{CI}:$ 1.2-5.1). However, after adjusting for other variables including race, gender, and coexisting morbidity, the association was no longer statistically significant (risk estimates not given). A population-based case-control study from Denmark included 598 adults with pneumococcal bacteremia and ten matched controls per case [119]. The crude OR for pneumococcal bacteremia in people with diabetes was 1.9 (95\% CI: $1.4-$ 2.6). After adjustment for comorbidity, the OR decreased to 1.5 (95\% CI: 1.1-2.0). In comparison, a similar subsequent case-control study found an adjusted OR of 1.3 (95\% CI: 1.2-1.3) for pneumonia hospitalization associated with diabetes [26]. Among the pneumonia patients, a similar proportion of diabetic and nondiabetic individuals were blood cultured ( $60 \%$ in both groups); the adjusted RRs for having any bacteremia in cultured diabetic vs non-diabetic patients was 1.02 (95\% CI 0.78-1.33); and for pneumococcal bacteremia was 1.17 (95\% CI 0.84-1.62). In conclusion, recent evidence suggests that diabetes is associated with a moderately (approximately 1.5-fold) increased risk of pneumococcal bacteremia, and that this risk increase is comparable with, or slightly higher than, the risk increase for pneumonia.

\section{Diabetes and Enterobacterial Bacteremia}

Although previous studies have reported an increased risk of UTI and in particular pyelonephritis, associated with diabetes (see above), there are few studies of the association with the most life-threatening consequence of UTI, bacteremia caused by gram-negative bacilli such as E. coli and other enterobacteria. Case-series from the beginning of the 2000s reported a diabetes prevalence of $20-30 \%$ among patients with enterobacterial bacteremia [120], and up to $40 \%$ among patients with community-acquired Klebsiella pneumoniae bacteremia [121]. East Asian cases series have reported a diabetes prevalence of approximately $75 \%$ among pyogenic liver abscess patients infected with Klebsiella pneumoniae [122, 123], and diabetes has since been confirmed as strong risk factor for pyogenic liver abscess in European and North American studies [124, 125].

Early cross-sectional studies of diverse bacteremias have estimated that the prevalence of enterobacterial bacteremia in diabetic patients was two- to threefold increased $[105,126]$.
In 2005, Jackson et al. [127] conducted a nested casecontrol study including 184 seniors with communityacquired $E$. coli bacteraemias and 769 matched controls. The prevalence of diabetes in bacteremia cases $v s$ controls was $21 \%$ vs $18 \%$ among men and $20 \%$ vs $9 \%$ among women. The authors stated that diabetes mellitus was associated with an increased risk of $E$. coli bacteremia from a urinary source in women in an age-adjusted model (OR 2.42, 95\% CI 1.404.17 ), yet diabetes was not selected for the final multivariate model [127]. In 2005, diabetes was examined as a risk and prognostic factor for community-acquired bacteremia caused by $E$. coli and other enterobacteria in Denmark [128]. This population-based case-control included 1,317 adult case patients and ten population controls per case and found that persons with diabetes had a substantially increased risk for enterobacterial bacteremia (adjusted odds ratio $=2.9,95 \%$ CI: 2.4-3.4). Among bacteremia patients, diabetes was furthermore associated with a poorer prognosis [128], whereas another cohort study from Spain found that diabetes was not associated with worse prognosis following Enterobacteriaceae bacteremia [129]. Laupland et al. conducted a population-based surveillance of $E$. coli bacteremia in a large Canadian region during 2000-2006 [130]. They estimated the approximate number of persons with diabetes and other risk factors based on Canadian survey data, suggesting that diabetic individuals may have a crude incidence rate ratio of $7.2(6.4-8.0)$ for $E$. coli bacteremia, not taking into account possible confounding by age and other comorbity however.

In conclusion, there is strong evidence that diabetes is associated with at least 2.5 to 3 times increased risk for bacteremia due to $E$. coli and other enterobacteria, which compares to the 2 times increased risk of cystitis and the up to 4 times increased risk of pyelonephritis discussed above, given that the majority of community-acquired bacteremias with enterobacteria are due to an UTI focus $[128,130]$.

\section{Diabetes and Streptococcal Bacteremia}

Hemolytic streptococci (HS) are an increasingly common cause of severe bacteremia and sepsis worldwide [131-133]. These infections are most often community-acquired and derived from a skin or soft-tissue or an unknown focus. In the U.S., the incidence of adult invasive group B streptococcal (GBS) infection has more than doubled between 1990 and 2007 to 7.3 cases per 100,000 persons in 2007, and now approaches the incidence of invasive pneumococcal infections in elderly people [134]. The increasing prevalence of adults with chronic medical conditions remains the most plausible explanation for the increasing incidence of adult invasive HS disease. In particular, several studies have indicated a strikingly high prevalence of diabetes among patients with invasive HS disease [135]. For GBS invasive disease, many case series from both North America, Asia and Europe have reported diabetes prevalences of approximately 30\% [136-143]. Among patients with severe GAS infections, $8 \%$ (with a wide range of $0 \%$ to $22 \%$ ) had diabetes in a recent 2 -year prospective surveillance study in 11 European countries [132]. In Denmark in 1999-2002, Ekelund et al. found comparable prevalences of diabetes in patients with invasive infection due to GAS (11\%), GBS (14\%) and GGS (16\%) [131]. Only two case-control studies of HS invasive disease 
have reported on the role of diabetes among a variety of risk factors. In Factor et al's GAS case-control study including 139 patients with invasive GAS disease in the US and Canada [144] the relative risk associated with diabetes was 2.1 among persons 18-44 years old (crude odds ratio (OR), $2.1 ; 95 \%$ confidence interval $(\mathrm{CI}), 0.6-7.1$ ) (adjusted OR not reported). Among persons 45+ years old the crude OR was $2.3(95 \%$ CI, 1.2-4.5) and the adjusted OR 2.3 (95\% CI, 1.14.8). In Jackson et al's GBS case-control study of 219 nonpregnant adult GBS cases the adjusted OR for diabetes was $3.0(95 \%$ CI, 1.9-4.7) [145].

Thus, there is increasing epidemiological evidence that bacteremia risk due to hemolytic streptococci may be increased 2 times in diabetes, and at least 3 times specifically for GBS bacteremia.

\section{Diabetes and Staphylococcal Bacteremia}

Staphylococcus aureus is a major cause of communityacquired bacteremia and severe sepsis worldwide, although most cases are health care related [146]. As for hemolytic streptococcal bacteremia, skin and soft tissue is an important focus for $S$. aureus bacteremia.

Laupland et al. conducted a population-based surveillance of Staphylococcus aureus bacteremia in a large Canadian region during 2000-2006 [146]. As in an earlier $E$. coli study [130], they estimated the approximate number of persons with diabetes and other risk factors based on Canadian survey data. They suggested diabetes may have a crude incidence rate ratio as high as 10.6 (95\% CI 9.3-11.9) for any $S$. aureus bacteremia, and 14.7 (10.4-20.6) for methicillin-resistant $S$. aureus (MRSA) bacteremia, not taking into account confounding by age and other comorbity however. A survey study of all cases of invasive $S$. aureus infections in western Sweden from March 2003 to February 2005 used similar methods, estimating the number of individuals in the background population with diabetes. The authors suggested that the incidence of invasive $S$. aureus infections may be 8.2 (95\% CI 6-12) times increased. No formal large population-based epidemiologic case-control or cohort studies, to our knowledge, have focused on diabetes as risk factor for $S$. aureus bacteremia.

Diabetic persons may have increased susceptibility to community-acquired streptococcal and staphylococcal bacteremia for several reasons, including tissue hyperglycemia and decreased oxygenation, and generally decreased immunity (see later). Mechanisms may also include shared risk factors for diabetes and skin or soft tissue infections, such as physical inactivity and obesity, which may lead to venous oedema and/or lymphoedema followed by relapsing erysipelas/cellulitis and ulcers of the leg [135, 147]. Moreover, diabetes per se may lead to peripheral vascular disease and neuropathy, and at least $15 \%$ of patients with diabetes will develop a foot ulcer in their lifetime [148, 149]. Moreover, diabetes is a major risk factor for chronic heart failure [150] that subsequently may lead to venous oedema, leg ulcers and infections. Correspondingly, the risk ratio for cellulitis $(=1.8 ; 95 \% \mathrm{CI}, 1.8-1.9)$ was among the highest for a range of examined infections among diabetic individuals in Ontario, Canada [29]. Cellulitis is a major focus of infection for GAS and GGS bacteraemia [131, 132, 151]. The risk of foot ulcers is known to increase with diabetes duration and poor glycemic control [148]. Some studies have suggested an increased prevalence of colonization with $S$. aureus in diabetic individuals [152], and colonization may be a risk factor for infection [153]. Insulin injections and blood glucose self monitoring may theoretically increase bacterial colonization, yet manifest infections after such penetrating traumas ("finger sepsis") are rarely reported [154].

\section{METHODOLOGICAL CHALLENGES WHEN EXA- MINING THE ASSOCIATION BETWEEN DIABETES AND COMMUNITY-ACQUIRED INFECTIONS}

\section{Increased Surveillance of Diabetic Patients for Infections}

Infection as a diabetic complication is still not mentioned much even in updated diabetes guidelines [27]. Yet, it is likely that patients with diabetes are generally more closely followed for development of infections by their caregivers, due to clinical experience and anticipated problems with glycemic regulation [119]. In some settings, diabetic patients have been provided with information leaflets and education about UTI and RTI risk and management, and this has been found to positively influence their health-seeking behavior in a Dutch randomized trial [155]. Also, physicians may be more likely to admit a diabetic patient with infection to the hospital, due to anticipated dysregulation, dehydration and worsening of diabetic complications [27]. Such bias would lead to overestimation of the relative risk of infection associated with diabetes in infection hospitalization studies. There is some evidence in the literature for increased hospitalization versus outpatient treatment of diabetic individuals with infection. Among Ontario residents with diabetes and matched controls $(\mathrm{N}=513,749$ in each group) the risk ratio was 1.21 (99\% CI: 1.20-1.22) for any infection in primary or secondary care, but 2.01 (99\% CI: 1.96-2.06) for infections requiring hospitalization. A U.S. cohort study suggested that diabetic persons who develop pneumonia are more likely to be hospitalized than nondiabetic persons (hospitalizations for pneumonia, adjusted $\mathrm{RR}=1.52$; outpatient visits for pneumonia, adjusted $R R=0.90$ ) [30]. These findings may be either due to hospitalization of a higher proportion of diabetic than non-diabetic persons with the same severity of infection, or may be due to increased severity of infection caused by diabetes, or both. For example, several studies found that compared with nondiabetes, diabetes confers a lower relative risk increase for URTI (which in many instances precedes LRTI) than for LRTI [29, 32]. Similar considerations may apply to the continuum of cystitis -> pyelonephritis -> urosepsis and Gram-negative bacteremia, or wound infection -> cellulitis $>$ streptococcal bacteremia. For the worst category in the infectious disease spectrum, bacteremia, there might furthermore be detection bias by more frequent blood cultures done in diabetic persons. However, earlier population-based studies of diabetes patients hospitalized with pneumococcal bacteremia [156] or pneumonia [40] showed that both pre-admission prescriptions of antibiotics, levels of inflammatory markers on admission, and proportions of patients with at least one blood culture were similar among patients with diabetes and nondiabetic patients. This suggests that there was no severe bias associated with surveillance and treatment of infected patients with diabetes in a population-based setting [40, 
156]. In conclusion, some surveillance bias is likely to be present, but it is unlikely to fully explain risk ratios of 1.5 to 2 or more as seen for many of the infections discussed above.

\section{Misclassification of Diabetes}

The risk of missing undetected diabetes may be greater for non-infected controls than for infected case patents in some studies [119], and stress hyperglycemia may be misinterpreted as diabetes in some cases, both leading to an overestimation of the relative risk of infection from diabetes. It may be preferable to collect data on diabetes exposure and possible confounding factors before the date of contact with infection [26].

\section{Uncontrolled Confounders}

Uncontrolled confounding may have affected relative risk estimates in many studies. In general, this may have lead to an overestimation of the relative risk of infection from diabetes, since many factors predictive of infection are expected to be more prevalent in diabetic than other persons. These diabetes-associated factors include increased age and associated immunosenescence, ethnicity, lifestyle factors such as smoking and alcohol overuse, socioeconomic factors including poorer housing, number of children in the household and crowding, possibly hygiene and sexual habits, a range of comorbidities as mentioned above, immunosuppressive therapies including glucocorticoids, and genetic immunodeficiencies such as mannose-binding lectine. Importantly, direct effects of diabetes should not be considered confounders in any study assessing the impact of diabetes on infection risk [157]. Such mediators of diabetes effect on infection risk may include diabetes complications such as cardiovascular or renal comorbidity, or drug treatment as a consequence of diabetes. Mediators may also include economic or lifestyle factors, e.g. alcohol overuse or inability to work, that may be negatively affected by receiving a chronic and sometimes invalidating diagnosis as diabetes. On the other hand, diabetic patients may also receive more infection-prophylactic interventions such as smoking cessation and immunizations [27], tending to decrease their risk of infection.

\section{SUGGESTED BIOLOGICAL MECHANISMS THAT MAY PLAY A ROLE IN THE ASSOCIATION BET- WEEN DIABETES AND COMMUNITY-ACQUIRED INFECTIONS}

\section{The Impact of Diabetes and Hyperglycemia on Inflammation and Immune Function}

Unlike type 2 diabetes which is often associated with hyperinsulinemia, type 1 diabetes is characterized by reduced or totally absent insulin secretion. It is well-known that insulin exerts anti-inflammatory signaling [158-160]. In contrast, hyperglycemia triggers robust proinflammatory responses demonstrable in vivo and in vitro [161, 162]. Since a variable proportion of type 2 diabetic patients and all type 1 diabetic patients are treated with external insulin to reduce their hyperglycemia, the net effect of these exposures becomes complicated to elucidate. It is well-substantiated however, that diabetes is associated with chronic low-grade inflammation. Elevated levels of C-reactive protein and interleukin 6 (IL-6) predict development of type 2 diabetes in healthy individuals [163], and manifest diabetes is associated with increased levels of circulating proinflammatory cytokines such as IL-6 [164].

Parallel with the chronic low-intensity inflammation, cytokine responses to an acute infectious challenge seem to be reduced in patients with diabetes. In a mice model of experimental sepsis, diabetic mice had a profound and wideranging suppression of systemic cytokine release compared to non-diabetic mice [161]. Among women with asymptomatic bacteriurua, those with diabetes had a lower concentration of IL- 6 in the urine compared with nondiabetic women, and their monocytes secreted less proinflammatory cytokines after stimulation with lipopolysaccharide in vitro [165]. Andreasen et al. exposed type 2 diabetic patients and healthy controls to an intravenous injection of $E$. coli lipopolysaccharide. They found that type 2 diabetes was associated with less pronounced lipopolysaccharide-induced increases in TNF and several other cytokine responses [166]. Others have hypothesized that deficiencies in the innate immune system may underly both increased diabetes risk and increased infection risk. For example, mannose-binding lectin deficiency has been associated with increased risk of type 1 diabetes, insulin resistance, and obesity [167]. Because mannose-binding lectin deficiency is associated with decreased inherent ability to sense and buffer environmental substances, it may lead to both increased low-grade chronic inflammation and increased risk of infection [168].

Concerning prognosis of infection, it has been speculated that diabetic patients with sepsis may be protected from severe complications, such as ARDS, via a less active inflammatory cascade [156, 169]. Recently, Esper et al. examined the impact of pre-existing diabetes on organ dysfunction among 12.5 million sepsis patients [170]. They concluded that diabetes patients, relative to non-diabetic individuals, were less likely to develop respiratory failure during the course of sepsis. On the other hand, diabetic patients were more likely to develop renal failure [170]. Also, while hyperglycemia is associated with decreased acute inflammation in humans with endotoxemia, hyperglycemia at the same time potentiates coagulation and may thus make diabetic patients especially vulnerable to prothrombotic events [15]. Cohort studies from Denmark [40] and Canada [41] have clearly demonstrated the association between glucose levels of more than $11 \mathrm{mmol} / \mathrm{L}$ on admssion and increased mortality following pneumonia, as discussed above. Interestingly, several studies have found that acutely high initial glucose levels on admission with severe infection are much stronger predictors of death in nondiabetic than in diabetic individuals, for example among patients with pneumonia [40, 41, 171] and sepsis [172].

Numerous in vitro studies have demonstrated that hyperglycemia can impair a range of functions in neutrophils and macrophages, including chemotaxis, adherence, phagocytosis, and intracellular killing of microorganisms, all of which may be important in limiting invasion by bacteria in vivo [173]. Kjersem et al. found that in polymorphonuclear leukocytes from T1 DM patients, the ingestion of particles coated with lipopolysaccharide from Escherichia coli became reduced during change from normoto hyperglycemia [174]. Others demonstrated that 
hyperglycemia impairs the generation in leukocytes of oxygen free radicals and hydrogen peroxide required for intracellular killing of microorganisms [175]. The clinical significance of these findings remains uncertain.

Thirty years ago, Rayfield et al. followed 241 diabetic patients at outpatient clinics in New York and noted a weak correlation between mean fasting plasma glucose levels and prevalence of subsequent infections [176]. The evidence from newer studies suggests that severely dysregulated diabetes increases a number of specific infections more than well-regulated diabetes does, this evidence is discussed in more detail above. Randomized trials have shown that surgical patients who are fed parenterally experience more infections as compared to patients on enteral nutrition, potentially associated with development of severe hyperglycemia [177, 178]. Randomized trials in patients undergoing surgery have shown that intensive insulin treatment with corresponding tight hyperglycemic control may reduce the risk of subsequent wound infections and sepsis in certain groups of diabetic and non-diabetic patients $[179,180]$. It is debated whether this observed effect may be due to reduced harm of hyperglycemia, or beneficial antiinflammatory effects of insulin [158]. Intensive glucose control increased mortality among adults in the ICU in the large international randomized NICE-SUGAR trial [181]. Therefore, very tight glycemic control in critical illness including severe sepsis is not recommended in updated guidelines, and more moderate recommendation to target a blood glucose concentration between $144 \mathrm{mg} / \mathrm{dL}$ and 180 $\mathrm{mg} / \mathrm{dL}(8-10 \mathrm{mmol} / \mathrm{L})$ in critical illness is currently advocated [182].

\section{Infections Causing Metabolic Derangement in Diabetes}

The metabolic responses to severe infection are similar to changes associated with trauma and include initial stimulation of gluconeogenesis by secretion of glucagon, cortisol, growth hormone and catecholamines and inhibition of insulin secretion. A subsequent increase in insulin secretion (in type 2 diabetes) is associated with marked insulin resistance, particularly in skeletal muscle and therefore with persistent hyperglycemia. Insulin resistance may be mediated by effects of interleukins and tumor necrosis factor on the insulin receptor [183]. Diabetic patients may thus be at risk of metabolic derangement caused by severe infection per se and risk a poorer prognosis of infection compared to non-diabetic patients. It has been known for long that infection and ketoacidosis frequently cooccur $[184,185]$, whereas it may be difficult to determine if hyperglycemia caused the infection or vice versa. During periods of influenza epidemics, an increased prevalence of hospitalizations with ketoacidosis has been observed [186]. Azoulay et al. studied 123 episodes of ketoacidosis in intensive care unit patients, and found that $41 \%$ had clinically or microbiologically documented infection. Lack of clearance of ketonuria within 12 hours was 3.7 times more frequent among patients with infection [187]. Gogos et al. studied 49 patients with ketoacidosis or hyperosmolar coma and signs of systemic inflammation, and found $45 \%$ of them to have infection; mortality in this group was $23 \%$ vs $7 \%$ in cases without infection [188].

\section{CONCLUSIONS}

There is now epidemiological evidence that individuals with diabetes have increased risk of some of the most frequent and severe community-acquired infections in society: respiratory tract infections, urinary tract infections, and bacteremia. This association is of major clinical and public health importance as the number of persons with diabetes is rapidly increasing. Compared with vascular diseases and other "classic" diabetes complications, infections have been a rather neglected area of diabetes research. Thus, the exact underlying mechanisms for the increased infection risk in patients with diabetes (including hyperglycemia, comorbidity, obesity, late diabetes complications, impaired immune function, and lifestyle factors) remain uncertain. In addition to prevention of diabetes, new research may focus on the relative importance of vaccines, patient and caregiver education, and modifiable risk factors among diabetic individuals, including good glycemic control, lifestyle factors, and existing antidiabetic drug therapies of which some (e.g. statins, metformin, insulin) may have beneficial effects against infections.

\section{CONFLICT OF INTEREST}

The authors confirm that this article content has no conflicts of interest.

\section{ACKNOWLEDGEMENTS}

Studies on diabetes and infection at the Department of Clinical Epidemiology were made possible through financial support from the Western Danish Research Forum for Health Sciences, the Danish Medical Research Council, "Det Obelske Familiefond", the Medical Research Council of North Jutland, the North Jutland County Medical Association, "Heinrich Kopp's Legat", the A. P. Møller Foundation for the Advancement of Medical Science, the Research Administration at Aalborg Hospital, the Institute of Clinical Medicine at Aarhus University Hospital, the Karen Elise Jensen Foundation, and Denmark's Lung Foundation.

\section{REFERENCES}

[1] Zimmet P, Alberti KG, Shaw J. Global and societal implications of the diabetes epidemic. Nature 2001; 414(6865): 782-7.

[2] Carstensen B, Kristensen JK, Ottosen P, Borch-Johnsen K. The Danish National Diabetes Register: trends in incidence, prevalence and mortality. Diabetologia 2008; 51(12): 2187-96.

[3] Danaei G, Finucane MM, Lu Y, et al. National, regional, and global trends in fasting plasma glucose and diabetes prevalence since 1980: systematic analysis of health examination surveys and epidemiological studies with 370 country-years and 2-À7 million participants. Lancet 2011; 378(9785): 31-40.

[4] Shaw JE, Sicree RA, Zimmet PZ. Global estimates of the prevalence of diabetes for 2010 and 2030. Diabetes Res Clin Pract 2010; 87(1): 4-14.

[5] Almdal T, Scharling H, Jensen JS, Vestergaard H. The independent effect of type 2 diabetes mellitus on ischemic heart disease, stroke, and death: a population-based study of 13,000 men and women with 20 years of follow-up. Arch Intern Med 2004; 164(13): 14226.

[6] Nolan CJ, Damm P, Prentki M. Type 2 diabetes across generations: from pathophysiology to prevention and management. Lancet 2009; 378(9786): 169-81.

[7] Roglic G, Unwin N. Mortality attributable to diabetes: estimates for the year 2010. Diabetes Res Clin Pract 2010; 87(1): 15-9. 
[8] McEwen LN, Kim C, Karter AJ, et al. Risk factors for mortality among patients with diabetes: the Translating Research Into Action for Diabetes (TRIAD) Study. Diabetes Care 2007; 30(7): 1736-41.

[9] Larkin JG, Frier BM, Ireland JT. Diabetes mellitus and infection. Postgrad Med J 1985; 61(713): 233-7.

[10] Boyko EJ, Lipsky BA: Infection and diabetes mellitus. In: Harris MI, Ed. Diabetes in America. $2^{\text {nd }}$ ed. Washington, DC: National Institutes of Health 1995; pp. 485-96.

[11] Tan JS. Infectious complications in patients with diabetes mellitus. Int Diabetes Monit 2000; 12(2): 1-7.

[12] Joshi N, Caputo GM, Weitekamp MR, Karchmer AW. Infections in patients with diabetes mellitus. N Engl J Med 1999; 341(25): 190612.

[13] Jackson LA. Evaluating diabetes mellitus as a risk factor for community-acquired infections. Clin Infect Dis 2005; 41(3): 28990.

[14] Peleg AY, Weerarathna T, McCarthy JS, Davis TME. Common infections in diabetes: pathogenesis, management and relationship to glycemic control. Diabetes Metab Res Rev 2007; 23(1): 3-13.

[15] Stegenga ME, van der Crabben SN, Blumer RME, et al. Hyperglycemia enhances coagulation and reduces neutrophil degranulation, whereas hyperinsulinemia inhibits fibrinolysis during human endotoxemia. Blood 2008; 112(1): 82-9.

[16] Foss-Freitas MC, Foss NT, Donadi EA, Foss MC. Effect of the glycemic control on intracellular cytokine production from peripheral blood mononuclear cells of type 1 and type 2 diabetic patients. Diabetes Res Clin Pract 2008; 82(3): 329-34.

[17] Pontin AR, Barnes RD, Joffe J, Kahn D. Emphysematous pyelonephritis in diabetic patients. Br J Urol 1995; 75(1): 71-4.

[18] Gill GV, Famuyiwa OO, Rolfe M, Archibald LK. Tropical diabetic hand syndrome. Lancet 1998; 351(9096): 113-4.

[19] Koh GC, Peacock SJ, van der Poll T, Wiersinga WJ. The impact of diabetes on the pathogenesis of sepsis. Eur J Clin Microbiol Infect Dis 2012; 31(4): 379-88.

[20] Heron M, Hoyert DL, Murphy SL, Xu J, Kochanek KD, TejadaVera B. Deaths: final data for 2006. Natl Vital Stat Rep 2009; 57(14): 1-134.

[21] Fry AM, Shay DK, Holman RC, Curns AT, Anderson LJ. Trends in hospitalizations for pneumonia among persons aged 65 years or older in the United States, 1988-2002. JAMA 2005; 294(21): 27129.

[22] Thomsen RW, Riis A, Norgaard M, et al. Rising incidence and persistently high mortality of hospitalized pneumonia: a 10-year population-based study in Denmark. J Intern Med 2006; 259(4): 410-7.

[23] Trotter CL, Stuart JM, George R, Miller E. Increasing hospital admissions for pneumonia, England. Emerging Infect Dis 2008; 14(5): 727-33

[24] Gageldonk-Lafeber AB, Bogaerts MA, Verheij RA, van der Sande MA. Time trends in primary-care morbidity, hospitalization and mortality due to pneumonia. Epidemiol Infect 2009; 137(10): 14728.

[25] Koziel H, Koziel MJ. Pulmonary complications of diabetes mellitus. Pneumonia. Infect Dis Clin North Am 1995; 9(1): 65-96.

[26] Kornum JB, Thomsen RW, Riis A, Lervang HH, Schonheyder HC, Sorensen HT. Diabetes, glycemic control, and risk of hospitalization with pneumonia: a population-based case-control study. Diabetes Care 2008; 31(8): 1541-5.

[27] American Diabetes Association. Standards of medical care in diabetes--2011. Diabetes Care 2011; 34 (Suppl 1): S11-61.

[28] Smith SA, Poland GA. Use of influenza and pneumococcal vaccines in people with diabetes. Diabetes Care 2000; 23(1): 95108 .

[29] Shah BR, Hux JE. Quantifying the risk of infectious diseases for people with diabetes. Diabetes Care 2003; 26(2): 510-3.

[30] Jackson ML, Neuzil KM, Thompson WW, et al. The burden of community-acquired pneumonia in seniors: results of a populationbased study. Clin Infect Dis 2004; 39(11): 1642-50.

[31] O'Meara ES, White M, Siscovick DS, Lyles MF, Kuller LH. Hospitalization for pneumonia in the Cardiovascular Health Study: incidence, mortality, and influence on longer-term survival. J Am Geriatr Soc 2005; 53(7): 1108-16.

[32] Muller LM, Gorter KJ, Hak E, et al. Increased risk of common infections in patients with type 1 and type 2 diabetes mellitus. Clin Infect Dis 2005; 41(3): 281-8.
[33] Benfield T, Jensen JS, Nordestgaard BG. Influence of diabetes and hyperglycaemia on infectious disease hospitalisation and outcome. Diabetologia 2007; 50(3): 549-54.

[34] Lipsky BA, Boyko EJ, Inui TS, Koepsell TD. Risk factors for acquiring pneumococcal infections. Arch Intern Med 1986; 146(11): 2179-85.

[35] Koivula I, Sten M, Makela PH. Risk factors for pneumonia in the elderly. Am J Med 1994; 96(4): 313-20.

[36] Lange P, Vestbo J, Nyboe J. Risk factors for death and hospitalization from pneumonia. A prospective study of a general population. Eur Respir J 1995; 8(10): 1694-8.

[37] Seshasai SR, Kaptoge S, Thompson A, et al. Diabetes mellitus, fasting glucose, and risk of cause-specific death. N Engl J Med 2011; 364(9): 829-41.

[38] Falguera M, Pifarre R, Martin A, Sheikh A, Moreno A. Etiology and outcome of community-acquired pneumonia in patients with diabetes mellitus. Chest 2005; 128(5): 3233-9.

[39] Yende S, van der PT, Lee M, et al. The influence of pre-existing diabetes mellitus on the host immune response and outcome of pneumonia: analysis of two multicentre cohort studies. Thorax 2010; 65(10): 870-7.

[40] Kornum JB, Thomsen RW, Riis A, Lervang HH, Schonheyder HC, Sorensen HT. Type 2 diabetes and pneumonia outcomes: a population-based cohort study. Diabetes Care 2007; 30(9): 2251-7.

[41] McAlister FA, Majumdar SR, Blitz S, Rowe BH, Romney J, Marrie TJ. The relation between hyperglycemia and outcomes in 2,471 patients admitted to the hospital with community-acquired pneumonia. Diabetes Care 2005; 28(4): 810-5.

[42] Vaillant L, La Ruche G, Tarantola A, Barboza P. Epidemiology of fatal cases associated with pandemic H1N1 influenza 2009. Eur Surveill 2009; 14(33): pii19309.

[43] Centers of Disease Control and Prevention. Bacterial coinfections in lung tissue specimens from fatal cases of 2009 pandemic influenza A (H1N1) - United States, May-August 2009. MMWR Morb Mortal Wkly Rep 2009; 58(38): 1071-4.

[44] Chandra RK. Immune response in overnutrition. Cancer Res 1981; 41(9 Pt 2): 3795-6.

[45] Falagas ME, Kompoti M. Obesity and infection. Lancet Infect Dis 2006; 6(7): 438-46.

[46] Kopelman PG. Obesity as a medical problem. Nature 2000; 404(6778): 635-43.

[47] Blumentals WA, Nevitt A, Peng MM, Toovey S. Body mass index and the incidence of influenza-associated pneumonia in a UK primary care cohort. Influenza Other Respi Viruses 2012; 6(1): 2836.

[48] Kornum JB, Norgaard M, Dethlefsen C, et al. Obesity and risk of subsequent hospitalisation with pneumonia. Eur Respir J 2010; 36(6): 1330-6.

[49] Fiore AE, Uyeki TM, Broder K, et al. Prevention and control of influenza with vaccines: recommendations of the Advisory Committee on Immunization Practices (ACIP), 2010. MMWR Recomm Rep 2010; 59(RR-8): 1-62.

[50] Nam JS, Kim AR, Yoon JC, et al. The humoral immune response to the inactivated influenza A (H1N1) 2009 monovalent vaccine in patients with Type 2 diabetes mellitus in Korea. Diabet Med 2011; 28(7): 815-7.

[51] Looijmans-van den Akker I, Verheij TJ, Buskens E, Nichol KL, Rutten GE, Hak E. Clinical effectiveness of first and repeat influenza vaccination in adult and elderly diabetic patients. Diabetes Care 2006; 29(8): 1771-6.

[52] Jackson LA, Jackson ML, Nelson JC, Neuzil KM, Weiss NS Evidence of bias in estimates of influenza vaccine effectiveness in seniors. Int J Epidemiol 2006; 35(2): 337-44.

[53] Jefferson T, Di Pietrantonj C, Rivetti A, Bawazeer GA, Al Ansary LA, Ferroni E. Vaccines for preventing influenza in healthy adults. Cochrane Database Syst Rev 2010; (7): CD001269.

[54] Jefferson T, Di Pietrantonj C, Al Ansary LA, Ferroni E, Thorning $\mathrm{S}$, Thomas RE. Vaccines for preventing influenza in the elderly. Cochrane Database Syst Rev 2010; (2): CD004876.

[55] Moberley SA, Holden J, Tatham DP, Andrews RM. Vaccines for preventing pneumococcal infection in adults. Cochrane Database Syst Rev 2008; (1): CD000422.

[56] Flynn JM. The changing cause of death in diabetes mellitus. Am J Med Sci 1935; 189: 157. 
[57] Restrepo BI. Convergence of the tuberculosis and diabetes epidemics: renewal of old acquaintances. Clin Infect Dis 2007; 45(4): 436-8.

[58] Joslin EP. The treatment of diabetes mellitus with observations based upon thirteen hundred cases. $2^{\text {nd }}$ ed. Philadelphia: Lea and Febiger 1917.

[59] Jacobsen ATB. Varige resultater af insulinbehandlingen. Hospitalstidende 1928; 33: 20-8.

[60] Stevenson CR, Critchley JA, Forouhi NG, et al. Diabetes and the risk of tuberculosis: a neglected threat to public health? Chronic Illn 2007; 3(3): 228-45.

[61] Jeon CY, Murray MB. Diabetes mellitus increases the risk of active tuberculosis: a systematic review of 13 observational studies. PLoS Med 2008; 5(7): e152.

[62] Pablos-Mendez A, Blustein J, Knirsch CA. The role of diabetes mellitus in the higher prevalence of tuberculosis among Hispanics. Am J Public Health 1997; 87(4): 574-9.

[63] Leung CC, Lam TH, Chan WM, et al. Diabetic control and risk of tuberculosis: a cohort study. Am J Epidemiol 2008; 167(12): 148694.

[64] Dobler CC, Flack JR, Marks GB. Risk of tuberculosis among people with diabetes mellitus: an Australian nationwide cohort study. BMJ Open 2012; 13(2): e000666.

[65] Leegaard A, Riis A, Kornum JB, et al. Diabetes, Glycemic Control, and Risk of Tuberculosis A population-based case-control study. Diabetes Care 2011; 34(12): 2530-5.

[66] Dooley KE, Chaisson RE. Tuberculosis and diabetes mellitus: convergence of two epidemics. Lancet Infect Dis 2009; 9(12): 73746.

[67] Faurholt-Jepsen D, Range N, Praygod G, et al. Diabetes is a risk factor for pulmonary tuberculosis: a case-control study from Mwanza, Tanzania. PLoS ONE 2011; 6(8): e24215

[68] Goldhaber-Fiebert JD, Jeon CY, Cohen T, Murray MB. Diabetes mellitus and tuberculosis in countries with high tuberculosis burdens: individual risks and social determinants. Int J Epidemiol 2011; 40(2): 417-28.

[69] Bashar M, Alcabes P, Rom WN, Condos R. Increased incidence of multidrug-resistant tuberculosis in diabetic patients on the Bellevue Chest Service, 1987 to 1997 . Chest 2001; 120(5): 1514-9.

[70] Fisher-Hoch SP, Whitney E, McCormick JB, et al. Type 2 diabetes and multidrug-resistant tuberculosis. Scand J Infect Dis 2008; 40(11-12): 888-93.

[71] Bischoff A, Ekoe T, Perone N, Slama S, Loutan L. Chronic disease management in Sub-Saharan Africa: whose business is it? Int $\mathrm{J}$ Environ Res Public Health 2009; 6(8): 2258-70.

[72] Beran D, Yudkin JS, de Court M. Access to care for patients with insulin-requiring diabetes in developing countries: case studies of Mozambique and Zambia. Diabetes Care 2005; 28(9): 2136-40.

[73] Boutayeb A. The double burden of communicable and noncommunicable diseases in developing countries. Trans R Soc Trop Med Hyg 2006; 100(3): 191-9.

[74] Gill GV, Mbanya JC, Ramaiya KL, Tesfaye S. A sub-Saharan African perspective of diabetes. Diabetologia 2009; 52(1): 8-16.

[75] Levitt NS. Diabetes in Africa: epidemiology, management and healthcare challenges. Heart 2008; 94(11): 1376-82.

[76] Young F, Critchley JA, Johnstone LK, Unwin NC. A review of comorbidity between infectious and chronic disease in Sub Saharan Africa: TB and diabetes mellitus, HIV and metabolic syndrome, and the impact of globalization. Global Health 2009; 5: 9.

[77] Foxman B, Barlow R, D'Arcy H, Gillespie B, Sobel JD. Urinary tract infection: self-reported incidence and associated costs. Ann Epidemiol 2000; 10(8): 509-15.

[78] Ronald AR, Nicolle LE, Stamm E, et al. Urinary tract infection in adults: research priorities and strategies. Int J Antimicrob Agents 2001; 17(4): 343-8.

[79] Stapleton A. Urinary tract infections in patients with diabetes. Am J Med 2002; 113 Suppl 1A: 80S-4.

[80] Funfstuck R, Nicolle LE, Hanefeld M, Naber KG. Urinary tract infection in patients with diabetes mellitus. Clin Nephrol 2012; 77(1): 40-8.

[81] Geerlings SE, Stolk RP, Camps MJ, et al. Asymptomatic bacteriuria may be considered a complication in women with diabetes. Diabetes Mellitus Women Asymptomatic Bacteriuria Utrecht Study Group. Diabetes Care 2000; 23(6): 744-9.

[82] Makuyana D, Mhlabi D, Chipfupa M, Munyombwe T, Gwanzura L. Asymptomatic bacteriuria among outpatients with diabetes mellitus in an urban black population. Cent Afr J Med 2002; 48(78): 78-82.

[83] Bonadio M, Boldrini E, Forotti G, et al. Asymptomatic bacteriuria in women with diabetes: influence of metabolic control. Clin Infect Dis 2004; 38(6): e41-5.

[84] Boyko EJ, Fihn SD, Scholes D, Abraham L, Monsey B. Risk of urinary tract infection and asymptomatic bacteriuria among diabetic and nondiabetic postmenopausal women. Am J Epidemiol 2005; 161(6): 557-64.

[85] Bonadio M, Costarelli S, Morelli G, Tartaglia T. The influence of diabetes mellitus on the spectrum of uropathogens and the antimicrobial resistance in elderly adult patients with urinary tract infection. BMC Infect Dis 2006; 6: 54.

[86] Harding GK, Zhanel GG, Nicolle LE, Cheang M. Antimicrobial treatment in diabetic women with asymptomatic bacteriuria. $\mathrm{N}$ Engl J Med 2002; 347(20): 1576-83.

[87] Czaja CA, Rutledge BN, Cleary PA, Chan K, Stapleton AE, Stamm WE. Urinary tract infections in women with type 1 diabetes mellitus: survey of female participants in the epidemiology of diabetes interventions and complications study cohort. J Urol 2009; 181(3): 1129-34

[88] Sanden AK, Johansen MB, Pedersen L, Lervang HH, Schonheyder HC, Thomsen RW. Change from oral antidiabetic therapy to insulin and risk of urinary tract infections in Type 2 diabetic patients: a population-based prescription study. J Diabetes Complications 2010; 24(6): 375-81.

[89] Boyko EJ, Fihn SD, Scholes D, Chen CL, Normand EH, Yarbro P. Diabetes and the risk of acute urinary tract infection among postmenopausal women. Diabetes Care 2002; 25(10): 1778-83.

[90] Brown JS, Vittinghoff E, Kanaya AM, Agarwal SK, Hulley S, Foxman B. Urinary tract infections in postmenopausal women: effect of hormone therapy and risk factors. Obstet Gynecol 2001; 98(6): 1045-52.

[91] Nicolle L, Zhanel G, Harding G. Microbiological outcomes in women with diabetes and untreated asymptomatic bacteriuria. World J Urol 2006; 24(1): 61-5.

[92] Scholes D, Hooton TM, Roberts PL, Gupta K, Stapleton AE, Stamm WE. Risk factors associated with acute pyelonephritis in healthy women. Ann Intern Med 2005; 142(1): 20-7.

[93] Kofteridis DP, Papadimitraki E, Mantadakis E, et al. Effect of diabetes mellitus on the clinical and microbiological features of hospitalized elderly patients with acute pyelonephritis. J Am Geriatr Soc 2009; 57(11): 2125-8.

[94] Efstathiou SP, Pefanis AV, Tsioulos DI, et al. Acute pyelonephritis in adults: prediction of mortality and failure of treatment. Arch Intern Med 2003; 163(10): 1206-12.

[95] Rassias AJ, Marrin CA, Arruda J, Whalen PK, Beach M, Yeager MP. Insulin infusion improves neutrophil function in diabetic cardiac surgery patients. Anesth Analg 1999; 88(5): 1011-6.

[96] Ingberg C, Palmer M, Schvarcz E, Åman J. Prevalence of urinary tract symptoms in long-standing type 1 diabetes mellitus. Diabetes Metab 1998; 24: 351-4.

[97] Ribera MC, Pascual R, Orozco D, Perez BC, Pedrera V, Gil V. Incidence and risk factors associated with urinary tract infection in diabetic patients with and without asymptomatic bacteriuria. Eur J Clin Microbiol Infect Dis 2006; 25(6): 389-93.

[98] Stapleton A. Urinary tract infections in patients with diabetes. Am J Med 2002; 113 (Suppl 1A): 80S-4.

[99] Geerlings SE, Meiland R, van Lith EC, Brouwer EC, Gaastra W, Hoepelman AI. Adherence of type 1-fimbriated Escherichia coli to uroepithelial cells: more in diabetic women than in control subjects. Diabetes Care 2002; 25(8): 1405-9.

[100] Thomsen RW, Jepsen P, Sorensen HT. Diabetes mellitus and pyogenic liver abscess: risk and prognosis. Clin Infect Dis 2007; 44(9): 1194-201.

[101] Hu KK, Boyko EJ, Scholes D, et al. Risk factors for urinary tract infections in postmenopausal women. Arch Intern Med 2004; 164(9): 989-93.

[102] Martin GS, Mannino DM, Eaton S, Moss M. The Epidemiology of Sepsis in the United States from 1979 through 2000. N Engl J Med 2003; 348(16): 1546-54.

[103] Sogaard M, Norgaard M, Dethlefsen C, Schonheyder HC. Temporal Changes in the Incidence and 30-Day Mortality associated with Bacteremia in Hospitalized Patients from 1992 through 2006: A Population-based Cohort Study. Clin Infect Dis 2011; 52(1): 61-9. 
[104] Bryan CS, Reynolds KL, Metzger WT. Bacteremia in diabetic patients: comparison of incidence and mortality with nondiabetic patients. Diabetes Care 1985; 8(3): 244-9.

[105] Carton JA, Maradona JA, Nuno FJ, Fernandez-Alvarez R, PerezGonzalez F, Asensi V. Diabetes mellitus and bacteraemia: a comparative study between diabetic and non-diabetic patients. Eur J Med 1992; 1(5): 281-7.

[106] Weiderpass E, Gridley G, Nyren O, Pennello G, Landstrom AS, Ekbom A. Cause-specific mortality in a cohort of patients with diabetes mellitus: a population-based study in Sweden. J Clin Epidemiol 2001; 54(8): 802-9.

[107] Tsai CL, Lee CC, Ma MH, et al. Impact of diabetes on mortality among patients with community-acquired bacteremia. J Infect 2007; 55(1): 27-33.

[108] Stoeckle M, Kaech C, Trampuz A, Zimmerli W. The role of diabetes mellitus in patients with bloodstream infections. Swiss Med Wkly 2008; 138(35-36): 512-9.

[109] Community-acquired pneumonia in adults in British hospitals in 1982-1983: a survey of aetiology, mortality, prognostic factors and outcome. The British Thoracic Society and the Public Health Laboratory Service. Q J Med 1987; 62(239): 195-220.

[110] Fine MJ, Smith MA, Carson CA, et al. Prognosis and outcomes of patients with community-acquired pneumonia. A meta-analysis. JAMA 1996; 275(2): 134-41.

[111] Johansson N, Kalin M, Tiveljung-Lindell A, Giske CG, Hedlund J. Etiology of Community-Acquired Pneumonia: Increased Microbiological Yield with New Diagnostic Methods. Clin Infect Dis 2010; 50(2): 202-9.

[112] File TM, Marrie TJ. Burden of Community-Acquired Pneumonia in North American Adults. Postgrad Med 2010; 122(2): 130-41.

[113] Basi SK, Marrie TJ, Huang JQ, Majumdar SR. Patients admitted to hospital with suspected pneumonia and normal chest radiographs: Epidemiology, microbiology, and outcomes. Am J Med 2004; 117(5): 305-11.

[114] Marrie TJ. Bacteraemic pneumococcal pneumonia: a continuously evolving disease. J Infect 1992; 24(3): 247-55.

[115] Nielsen SV, Henrichsen J. Incidence of invasive pneumococcal disease and distribution of capsular types of pneumococci in Denmark, 1989-94. Epidemiol Infect 1996; 117(3): 411-6.

[116] Gransden WR, Eykyn SJ, Phillips I. Pneumococcal bacteraemia: 325 episodes diagnosed at St Thomas's Hospital. Br Med J (Clin Res Ed) 1985; 290(6467): 505-8.

[117] Watanakunakorn C, Greifenstein A, Stroh K, et al. Pneumococcal bacteremia in three community teaching hospitals from 1980 to 1989. Chest 1993; 103(4): 1152-6.

[118] Nuorti JP, Butler JC, Farley MM, et al. Cigarette smoking and invasive pneumococcal disease. Active Bacterial Core Surveillance Team. N Engl J Med 2000; 342(10): 681-9.

[119] Thomsen RW, Hundborg HH, Lervang HH, Johnsen SP, Schonheyder HC, Sorensen HT. Risk of community-acquired pneumococcal bacteremia in patients with diabetes: a populationbased case-control study. Diabetes Care 2004; 27(5): 1143-7.

[120] Graff LR, Franklin KK, Witt L, et al. Antimicrobial therapy of gram-negative bacteremia at two university-affiliated medical centers. Am J Med 2002; 112(3): 204-11.

[121] Ko WC, Paterson DL, Sagnimeni AJ, et al. Community-acquired Klebsiella pneumoniae bacteremia: global differences in clinical patterns. Emerging Infect Dis 2002; 8(2): 160-6.

[122] Wang JH, Liu YC, Lee SSJ, et al. Primary liver abscess due to Klebsiella pneumoniae in Taiwan. Clin Infect Dis 1998; 26(6): 1434-8.

[123] Tsai FC, Huang YT, Chang LY, Wang JT. Pyogenic liver abscess as endemic disease, Taiwan. Emerging Infect Dis 2008; 14(10): 1592-600.

[124] Thomsen RW, Jepsen P, Sorensen HT. Diabetes mellitus and pyogenic liver abscess: risk and prognosis. Clin Infect Dis 2007; 44(9): 1194-201.

[125] Kaplan GG, Gregson DB, Laupland KB. Population-based study of the epidemiology of and the risk factors for pyogenic liver abscess. Clin Gastroenterol Hepatol 2004; 2(11): 1032-8.

[126] Guérin JM. Septicémies chez le diabétique. Sem Hop Paris 1992; 68: $176-9$.

[127] Jackson LA, Benson P, Neuzil KM, Grandjean M, Marino JL. Burden of Community-Onset Escherichia coli Bacteremia in Seniors. J Infect Dis 2005; 191(9): 1523-9.
[128] Thomsen RW, Hundborg HH, Lervang HH, Johnsen SP, Schonheyder HC, Sorensen HT. Diabetes mellitus as a risk and prognostic factor for community-acquired bacteremia due to enterobacteria: a 10-year, population-based study among adults. Clin Infect Dis 2005; 40(4): 628-31.

[129] Peralta G, Sanchez MB, Roiz MP, Garrido JC, Teira R, Mateos F. Diabetes does not affect outcome in patients with Enterobacteriaceae bacteremia. BMC Infect Dis 2009; 9: 94.

[130] Laupland KB, Gregson DB, Church DL, Ross T, Pitout JDD. Incidence, risk factors and outcomes of Escherichia coli bloodstream infections in a large Canadian region. Clin Microbiol Infect 2008; 14(11): 1041-7.

[131] Ekelund K, Skinhoj P, Madsen J, Konradsen HB. Invasive group A, B, C and G streptococcal infections in Denmark 1999-2002: epidemiological and clinical aspects. Clin Microbiol Infect 2005; 11(7): 569-76.

[132] Lamagni TL, Darenberg J, Luca-Harari B, et al. Epidemiology of severe Streptococcus pyogenes disease in Europe. J Clin Microbiol 2008; 46(7): 2359-67.

[133] Laupland KB, Ross T, Church DL, Gregson DB. Population-based surveillance of invasive pyogenic streptococcal infection in a large Canadian region. Clin Microbiol Infect 2006; 12(3): 224-30.

[134] Skoff TH, Farley MM, Petit S, et al. Increasing burden of invasive group B streptococcal disease in nonpregnant adults, 1990-2007. Clin Infect Dis 2009; 49(1): 85-92.

[135] Sendi P, Johansson L, Norrby-Teglund A. Invasive group B streptococcal disease in non-pregnant adults. Infection 2008; 36(2): 100-11.

[136] Opal SM, Cross A, Palmer M, Almazan R. Group B streptococcal sepsis in adults and infants. Contrasts and comparisons. Arch Intern Med 1988; 148(3): 641-5.

[137] Schwartz B, Schuchat A, Oxtoby MJ, Cochi SL, Hightower A, Broome CV. Invasive group B streptococcal disease in adults. A population-based study in metropolitan Atlanta. JAMA 1991; 266(8): 1112-4.

[138] Farley MM, Harvey RC, Stull T, et al. A population-based assessment of invasive disease due to group B Streptococcus in nonpregnant adults. N Engl J Med 1993; 328(25): 1807-11.

[139] Munoz P, Llancaqueo A, Rodriguez-Creixems M, Pelaez T, Martin L, Bouza E. Group B streptococcus bacteremia in nonpregnant adults. Arch Intern Med 1997; 157(2): 213-6.

[140] Perovic O, Crewe-Brown HH, Khoosal M, Karstaedt AS. Invasive group B streptococcal disease in nonpregnant adults. Eur J Clin Microbiol Infect Dis 1999; 18(5): 362-4.

[141] Tyrrell GJ, Senzilet LD, Spika JS, et al. Invasive disease due to group B streptococcal infection in adults: results from a Canadian, population-based, active laboratory surveillance study--1996. Sentinel Health Unit Surveillance System Site Coordinators. J Infect Dis 2000; 182(1): 168-73

[142] Blancas D, Santin M, Olmo M, Alcaide F, Carratala J, Gudiol F. Group B streptococcal disease in nonpregnant adults: incidence, clinical characteristics, and outcome. Eur J Clin Microbiol Infect Dis 2004; 23(3): 168-73.

[143] Matsubara K, Yamamoto G. Invasive group B streptococcal infections in a tertiary care hospital between 1998 and 2007 in Japan. Int J Infect Dis 2009; 13(6): 679-84.

[144] Factor SH, Levine OS, Schwartz B, et al. Invasive group A streptococcal disease: risk factors for adults. Emerging Infect Dis 2003; 9(8): 970-7.

[145] Jackson LA, Hilsdon R, Farley MM, et al. Risk factors for group B streptococcal disease in adults. Ann Intern Med 1995; 123(6): 415 20 .

[146] Laupland KB, Ross T, Gregson DB. Staphylococcus aureus bloodstream infections: risk factors, outcomes, and the influence of methicillin resistance in Calgary, Canada, 2000-2006. J Infect Dis 2008; 198(3): 336-43.

[147] Cox NH. Oedema as a risk factor for multiple episodes of cellulitis/erysipelas of the lower leg: a series with community follow-up. Br J Dermatol 2006; 155(5): 947-50.

[148] Cheer K, Shearman C, Jude EB. Managing complications of the diabetic foot. BMJ 2009; 339: b4905.

[149] Lipsky B, Tabak Y, Johannes R, Vo L, Hyde L, Weigelt J. Skin and soft tissue infections in hospitalised patients with diabetes: culture isolates and risk factors associated with mortality, length of stay and cost. Diabetologia 2010; 53(5): 914-23. 
[150] Thomsen RW, Kasatpibal N, Riis A, Norgaard M, Sorensen HT. The impact of pre-existing heart failure on pneumonia prognosis: population-based cohort study. J Gen Intern Med 2008; 23(9): 1407-13.

[151] Wong SS, Lin YS, Mathew L, Rajagopal L, Sepkowitz D. Increase in group $\mathrm{G}$ streptococcal infections in a community hospital, New York, USA. Emerging Infect Dis 2009; 15(6): 991-3.

[152] Lipsky BA, Pecoraro RE, Chen MS, Koepsell TD. Factors affecting staphylococcal colonization among NIDDM outpatients. Diabetes Care 1987; 10(4): 483-6.

[153] von Eiff C, Becker K, Machka K, Stammer H, Peters G. Nasal carriage as a source of Staphylococcus aureus bacteremia. Study Group. N Engl J Med 2001; 344(1): 11-6.

[154] Monami M, Mannucci E, Masotti G. Finger sepsis in two poorly controlled diabetic patients with reuse of lancets. Diabetes Care 2002; 25(6): 1103

[155] Venmans LMAJ, Gorter KJ, Hak E, Rutten GEHM. Short-Term Effects of an Educational Program on Health-Seeking Behavior for Infections in Patients With Type 2 Diabetes: A randomized controlled intervention trial in primary care. Diabetes Care 2008; 31(3): 402-7.

[156] Thomsen RW, Hundborg HH, Lervang HH, Johnsen SP, Sorensen HT, Schonheyder HC. Diabetes and outcome of communityacquired pneumococcal bacteremia: a 10-year population-based cohort study. Diabetes Care 2004; 27(1): 70-6.

[157] Rothman KJ. Epidemiology: an introduction. $1^{\text {st }}$ ed. New York: Oxford University Press 2002.

[158] Das UN. Is insulin an antiinflammatory molecule? Nutrition 2001; 17(5): 409-13.

[159] Hansen TK, Thiel S, Wouters PJ, Christiansen JS, van den Berghe G. Intensive insulin therapy exerts antiinflammatory effects in critically ill patients and counteracts the adverse effect of low mannose-binding lectin levels. J Clin Endocrinol Metab 2003; 88: 1082-8.

[160] Brix-Christensen V, Andersen SK, Andersen R, et al. Acute hyperinsulinemia restrains endotoxin-induced systemic inflammatory response. Anesthesiology 2004; 100(4): 861-70.

[161] Osuchowski MF, Craciun FL, Schuller E, Sima C, Gyurko R, Remick DG. Untreated type 1 diabetes increases sepsis-induced mortality without inducing a prelethal cytokine response. Shock 2010; 34(4): 369-76.

[162] Dandona P, Chaudhuri A, Ghanim H, Mohanty P. Antiinflammatory effects of insulin and the pro-inflammatory effects of glucose. Semin Thorac Cardiovasc Surg 2006; 18(4): 293-301.

[163] Pradhan AD, Manson JE, Rifai N, Buring JE, Ridker PM. Creactive protein, interleukin 6 , and risk of developing type 2 diabetes mellitus. JAMA 2001; 286(3): 327-34.

[164] Jain SK, Kannan K, Lim G, Matthews-Greer J, McVie R, Bocchini JA, Jr. Elevated blood interleukin-6 levels in hyperketonemic type 1 diabetic patients and secretion by acetoacetate-treated cultured U937 monocytes. Diabetes Care 2003; 26(7): 2139-43.

[165] Geerlings SE, Brouwer EC, Van Kessel KC, Gaastra W, Stolk RP, Hoepelman AI. Cytokine secretion is impaired in women with diabetes mellitus. Eur J Clin Invest 2000; 30(11): 995-1001.

[166] Andreasen AS, Pedersen-Skovsgaard T, Berg RM, et al. Type 2 diabetes mellitus is associated with impaired cytokine response and adhesion molecule expression in human endotoxemia. Intensive Care Med 2010; 36(9): 1548-55.

[167] Muller YL, Hanson RL, Bian L, et al. Functional variants in MBL2 are associated with type 2 diabetes and pre-diabetes traits in Pima Indians and the old order Amish. Diabetes 2010; 59(8): 2080-5.

[168] Fernandez-Real JM, Straczkowski M, Vendrell J, et al. Protection from inflammatory disease in insulin resistance: the role of mannan-binding lectin. Diabetologia 2006; 49(10): 2402-11.
[169] Moss M, Guidot DM, Steinberg KP, et al. Diabetic patients have a decreased incidence of acute respiratory distress syndrome. Crit Care Med 2000; 28(7): 2187-92.

[170] Esper AM, Moss M, Martin GS. The effect of diabetes mellitus on organ dysfunction with sepsis: an epidemiological study. Crit Care 2009; 13(1): R18.

[171] Castellanos MR, Szerszen A, Saifan C, et al. Fasting hyperglycemia upon hospital admission is associated with higher pneumonia complication rates among the elderly. Int Arch Med 2010; 3: 16 .

[172] Schuetz P, Jones AE, Howell MD, et al. Diabetes Is Not Associated With Increased Mortality in Emergency Department Patients With Sepsis. Ann Emerg Med 2011; 58(5): 438-44.

[173] Delamaire M, Maugendre D, Moreno M, Le Goff MC, Allannic H, Genetet B. Impaired leucocyte functions in diabetic patients. Diabet Med 1997; 14(1): 29-34.

[174] Kjersem H, Hilsted J, Madsbad S, Wandall JH, Johansen KS, Borregaard N. Polymorphonuclear leucocyte dysfunction during short term metabolic changes from $\mathrm{n}$. Infection 1988; 16(4): 21521.

[175] Marhoffer W, Stein M, Schleinkofer L, Federlin K. Evidence of ex vivo and in vitro impaired neutrophil oxidative burst and phagocytic capacity in type 1 diabetes mellitus. Diabetes Res Clin Pract 1993; 19(3): 183-8.

[176] Rayfield EJ, Ault MJ, Keusch GT, Brothers MJ, Nechemias C, Smith H. Infection and diabetes: the case for glucose control. Am J Med 1982; 72(3): 439-50.

[177] Perioperative total parenteral nutrition in surgical patients. The Veterans Affairs Total Parenteral Nutrition Cooperative Study Group. N Engl J Med 1991; 325(8): 525-32.

[178] Moore FA, Feliciano DV, Andrassy RJ, et al. Early enteral feeding, compared with parenteral, reduces postoperative septic complications. The results of a meta-analysis. Ann Surg 1992; 216(2): 172-83.

[179] Furnary AP, Zerr KJ, Grunkemeier GL, Starr A. Continuous intravenous insulin infusion reduces the incidence of deep sternal wound infection in diabetic patients after cardiac surgical procedures. Ann Thorac Surg 1999; 67(2): 352-60.

[180] Van den Berghe G, Wouters P, Weekers F, et al. Intensive insulin therapy in critically ill patients. N Engl J Med 2001; 345(19): 135967.

[181] Finfer S, Chittock DR, Su SY, et al. Intensive versus conventional glucose control in critically ill patients. N Engl J Med 2009; 360(13): 1283-97.

[182] Egi M, Finfer S, Bellomo R. Glycemic control in the ICU. Chest 2011; 140(1): 212-20.

[183] Johnston CLW. Infection and diabetes mellitus. In: Pickup J, Williams G, Eds. Textbook of diabetes. Oxford: Blackwell Science 1997; pp. 1-14.

[184] Campbell IW, Munro JF, McCuish AC, Duncan LJ. Infection and severe diabetic metabolic decompensation. Practitioner 1974; 213(1278): 813-8.

[185] Soler NG, Bennett MA, Fitzgerald MG, Malins JM. Intensive care in the management of diabetic ketoacidosis. Lancet 1973; 1(7810): 951-4.

[186] Watkins PJ, Soler NG, Fitzgerald MG, Malins JM. Diabetic ketoacidosis during the influenza epidemic. Br Med J 1970; 4(727): 89-91.

[187] Azoulay E, Chevret S, Didier J, et al. Infection as a trigger of diabetic ketoacidosis in intensive care-unit patients. Clin Infect Dis 2001; 32(1): 30-5.

[188] Gogos CA, Giali S, Paliogianni F, Dimitracopoulos G, Bassaris HP, Vagenakis AG. Interleukin-6 and C-reactive protein as early markers of sepsis in patients with diabetic ketoacidosis or hyperosmosis. Diabetologia 2001; 44(8): 1011-4. 